\title{
Hierarchical porous carbon foam supported on carbon cloth as high-performance anodes for aqueous supercapacitors
}

\author{
Jie Zhang ${ }^{\text {a,b }}$, Wenli Li ${ }^{\text {a,b }}$, Tofik Ahmed Shifa ${ }^{c}$, Jiangbo Sun ${ }^{\text {a }}$, Chuqiao Jia ${ }^{\text {a }}$, Yumin Zhao ${ }^{\text {a }}$, \\ Yanbin Cui ${ }^{\text {a, b, * }}$ \\ a State Key Laboratory of Multiphase Complex Systems, Institute of Process Engineering, Chinese Academy of Sciences, Beijing, 100190, China \\ ${ }^{\mathrm{b}}$ Center of Materials Science and Optoelectronics Engineering, University of Chinese Academy of Sciences, Beijing, 100049, China \\ ${ }^{\mathrm{c}}$ Department of Engineering Science and Mathematics, Experimental Physics and Material Science Division, Lulea University of Technology, Sweden
}

\section{H I G H L I G H T S}

- Hierarchical porous carbon foam on CC was fabricated.

- Widened voltage window can be achieved through electrochemical reduction.

- An exceptional energy density of $10.07 \mathrm{mWh} / \mathrm{cm}^{3}$ was obtained for asymmetric device.

\section{G R A P H I C A L A B S T R A C T}
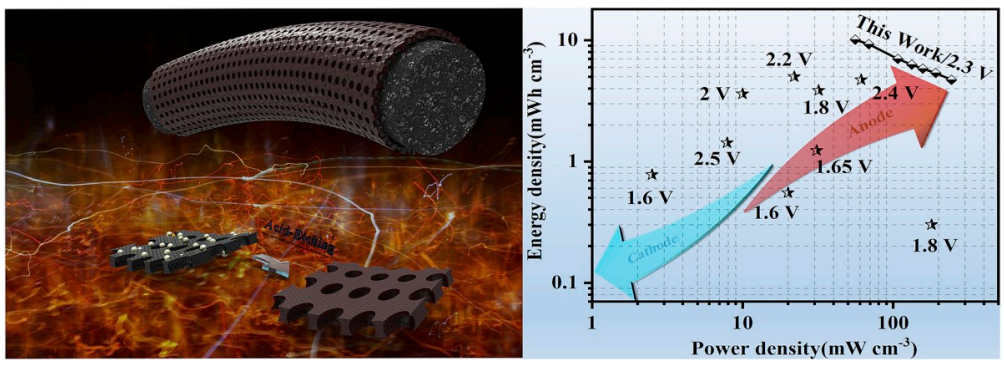

\section{A B S T R A C T}

Carbon anodes have been widely utilized for the fabrication of high-performance asymmetric supercapacitors. However, they generally suffer from unsatisfactory energy density due to low specific capacitance arising from inferior conductivity and insufficient ionic diffusion rate. Here a surface modification method is conducted after the annealing of ZIF-67 precursor to produce hydrophilic, porous and heteroatom-doped carbon foam. On top of enhanced area capacitance, widened voltage window of $-1.3-0 \mathrm{~V}$ (vs saturated calomel electrode) can be achieved through electrochemical reduction to suppress the hydrogen evolution reaction. The optimized reduced porous carbon foam on carbon cloth exhibits a maximum area capacitance of $1049 \mathrm{mF} / \mathrm{cm}^{2}$ at an applied current density of $12 \mathrm{~mA} / \mathrm{cm}^{2}$ with excellent capacitance retention of $98.4 \%$ after 6000 charge-discharge cycles at $15 \mathrm{~mA} / \mathrm{cm}^{2}$. By well pairing with hierarchical $\mathrm{MnO}_{2} / \mathrm{CC}$ cathode, a $2.3 \mathrm{~V}$ asymmetric supercapacitor in neutral aqueous $\mathrm{Na}_{2} \mathrm{SO}_{4}$ electrolyte is assembled, which delivers an exceptional energy density of up to $10.07 \mathrm{mWh} / \mathrm{cm}^{3}$. The procedure in this paper for carbonaceous material to simultaneously achieve considerable capacitance and enlarged voltage window can open up a wider prospect toward design of anodes for high-performance aqueous supercapacitor.

\footnotetext{
* Corresponding author. State Key Laboratory of Multiphase Complex Systems, Institute of Process Engineering, Chinese Academy of Sciences, Beijing, 100190, China.

E-mail address: ybcui@ipe.ac.cn (Y. Cui).
} 


\section{Introduction}

The rational design and efficient utilization of electrical energy devices have been regarded as complementary alternatives to solve the ineluctable global energy crisis. Of these devices, supercapacitor (SC), as a booming class of high-efficiency and light weight electronic device, won tremendous attention recently. The state-of-the-art investigation in this area is devoted to the effort in increasing energy density and operating voltage without sacrificing power density and long-term stability [1-5]. Asymmetric supercapacitors (ASCs) with two dissimilar electrode materials at different working potentials offer a distinct advantage of wide operational voltage window $[3,6]$. However, the stable voltage window for ASCs in aqueous electrolyte is thermodynamically limited to less than $1.23 \mathrm{~V}$ and the total capacitance would be severely limited by the anodes $[7,8]$. Therefore, one of the key issues is to develop anodes with both high capacitance and overpotential $(\eta)$ for respective hydrogen evolution reaction (HER), which, however, remains a significant challenge $[9,10]$.

Generally, cathode counterparts of ASCs are pseudocapacitive with high capacitance, while the anodes are prepared by carbonaceous materials with low capacitance and high chemical stability [11-14]. To balance the charges, thicker anodes are used in ACSs which eventually degrade the rate performance. Among carbonaceous materials, three-dimensional (3D) carbon architecture with robust framework offers high-efficient charge delivery and it is recognized as a promising electrode material $[15,16]$. Based on the reported results in literature, the direct introduction of hetero-atom into $\mathrm{sp}^{2}$-hybridized carbon matrix would effectively favor ionic penetration as well as intrinsic conductivity [17-20]. As such, a wide range of hetero-atom such as nitrogen [21], sulfur [22], phosphorus [23], and oxygen [24] have been reported as dopant in different carbon allotropes to improve the electrical conductivity, surface chemical activity and specific capacitance [25]. However, the extent of capacitance improvement by hetero-atom doping is still far from the value of faradaic reactions. An alternative strategy to further motivate the migration of ions and provide extra capacitance for taking full potentials of 3D carbon framework can be surface modification. Besides, most of the pre-mentioned 3D carbon anodes are in powder forms, in which unwanted conductive additives and binder need be added to make compact films [9,26,27]. These "dead mass" blocks the active sites and hardly meet the flexibility requirement for the potential usage in flexible electronics [28,29].

Based on the above introduction, specially designed porous carbon foam on carbon cloth (PCF/CC) was first achieved by in situ carbonization of ZIF-67, leading to highly conductive matrix and abundant multimodal pores. Subsequent electro-etching procedure with mixed acid was applied on PCF/CC to remove unstable Co nanoparticles and simultaneously modify outer surface for the improvement of capacitance. Reduced porous carbon foam on CC (RPCF/CC) with adsorbed $\mathrm{Na}^{+}$ions and reducing oxygen functionalities prepared by final electroreduction delivers enlarged voltage window of $-1.3-0 \mathrm{~V}$ arising from reducing activity of hydrogen evolution reaction. In our setup, we found that an asymmetric supercapacitor composed of hierarchical $\mathrm{MnO}_{2} / \mathrm{CC}$ $\left(\mathrm{H}-\mathrm{MnO}_{2} / \mathrm{CC}\right)$ cathode and $\mathrm{RPCF} / \mathrm{CC}$ anode in aqueous electrolytes displays a large operating window of $2.3 \mathrm{~V}$, an ultrahigh volumetric energy of $10.07 \mathrm{mWh} / \mathrm{cm}^{3}$ and an outstanding volumetric power of $55.8 \mathrm{~mW} / \mathrm{cm}^{3}$.

\section{Experimental section}

\subsection{Preparation of ZIF-67/CC and carbonization}

All chemicals were used without further purification. Self-supported ZIF-67 nanowall arrays on CC were fabricated by a solution method. In detail, $\mathrm{Co}\left(\mathrm{NO}_{3}\right)_{2} \cdot 6 \mathrm{H}_{2} \mathrm{O}(8 \mathrm{mmol})$ and 2-methylimidazole $(24 \mathrm{mmol})$ aqueous solution were quickly mixed together. Then, a piece of $\mathrm{HNO}_{3}$ soaked CC substrate $\left(2 \times 1 \times 0.033 \mathrm{~cm}^{3}\right)$ was immersed into the mixture fixed by adhesive tapes. After stirring for $24 \mathrm{~h}$, the resulting sample was taken out, cleaned with deionized water, and finally dried in vacuum at $60^{\circ} \mathrm{C}$. A combustion boat loaded with ZIF-67/CC was put into a tube furnace and annealed at $850^{\circ} \mathrm{C}$ for $100 \mathrm{~min}$ with a ramp rate of $5{ }^{\circ} \mathrm{C}$ $\min ^{-1}$ under Ar atmosphere to convert the ZIF-67 precursor into carbon foam.

\subsection{Preparation of $R P C F / C C$}

A piece of as-prepared PCF/CC sample was immersed in a mixture of $25 \mathrm{~mL}$ of $98 \% \mathrm{H}_{2} \mathrm{SO}_{4}$ and $25 \mathrm{~mL}$ of $70 \% \mathrm{HNO}_{3}$ with Pt foil as counter electrode and saturated calomel electrode (SCE) as reference electrode under a constant voltage of $3 \mathrm{~V}$ for $200 \mathrm{~s}$. After electro-etching process, the sample was rinsed with DI water several times. Finally, the sample was treated in $1 \mathrm{M} \mathrm{Na}_{2} \mathrm{SO}_{4}$ electrolyte at $25 \mathrm{mV} / \mathrm{s}$ in the potential window of $-1.5-0 \mathrm{~V}$ (vs SCE) and conducted for 300 cycles to obtain RPCF/ CC. The mass loading of carbon foam on carbon cloth is $\approx 1.5 \mathrm{mg} \mathrm{cm}^{-2}$.

\subsection{Fabrication of an asymmetric supercapacitor}

Asymmetric supercapacitor $\left(\mathrm{H}-\mathrm{MnO}_{2} / \mathrm{CC} / / \mathrm{RPCF} / \mathrm{CC}\right)$ was assembled using $1 \mathrm{M} \mathrm{Na}_{2} \mathrm{SO}_{4}$ electrolyte. The $\mathrm{H}-\mathrm{MnO}_{2} / \mathrm{CC}$ cathode was fabricated using a modification method as follows [30]: a piece of carbon cloth $\left(2 \times 1 \mathrm{~cm}^{2}, 0.33 \mathrm{~mm}\right.$ in thickness $)$ was used as working electrode in a $\mathrm{Mn}\left(\mathrm{CH}_{3} \mathrm{COO}\right)_{2} \cdot 4 \mathrm{H}_{2} \mathrm{O}(0.4 \mathrm{M})$ and $\mathrm{Na}_{2} \mathrm{SO}_{4}(0.6 \mathrm{M})$ solution at a constant potential of $3 \mathrm{~V}$ for $180 \mathrm{~s}$. The electrode was then dispersed in $50 \mathrm{~mL}$ of $0.5 \mathrm{M} \mathrm{H}_{2} \mathrm{SO}_{4}$ aqueous solution and maintained at $60^{\circ} \mathrm{C}$ for $4 \mathrm{~h}$. Prior to assembling, a piece of cellulose paper (NKK-MPF30AC-100, Japan) was soaked in a $1 \mathrm{M} \mathrm{Na}_{2} \mathrm{SO}_{4}$ aqueous solution for $10 \mathrm{~min}$ and then carefully entangled with the $\mathrm{H}-\mathrm{MnO}_{2} / \mathrm{CC}$ cathode and RPCF/CC anode. Eventually, a thin parafilm was wrapped on ASC.

\subsection{Materials characterization}

The morphology and microstructure of the samples were characterized by scanning electronic microscope (SEM, JEM-7001F) and transmission electron microscope (TEM, JEOL-2100). The specific surface area and pore size distribution of the electrode materials were examined by $\mathrm{N}_{2}$ sorption isotherms (BET, Quantachrome ASIQM0000-5). The crystallographic structures were investigated by a Rigaku Smartlab Xray diffractometer using $\mathrm{Cu} \mathrm{K} \alpha$ radiation. Raman spectra were recorded by a confocal laser inVia Raman microscope (Renishaw, $\lambda_{e}=514 \mathrm{~nm}$ ). Surface composition was analyzed by X-ray photoelectron spectroscopy (XPS, ESCALAB 250Xi, Thermal-Fisher). The water contact angle was measured by optical contact angle measurement system (DSA100S, KRUSS GmbH, Germany). All electrochemical tests were performed at room temperature. Cyclic voltammetry (CV), galvanostatic charge/ discharge (GCD) as well as electrochemical impedance spectroscopy (EIS) of the individual electrodes were implemented by a familiar threeelectrode system with a Pt counter electrode and a SCE reference electrode.

\section{Results and discussions}

Metal organic framework (MOF)-derived PCF/CC was initially prepared by a solution route and confined thermolysis. Owing to high carbon contents, ZIF-67 can be directly converted into carbon-metal porous materials without a secondary carbon precursor. The thermal treatment at $750{ }^{\circ} \mathrm{C}$ induced the conversion of imidazolate groups to carbonaceous forms along with the formation of meso-pores [31]. Further increasing the annealing temperature to $850^{\circ} \mathrm{C}$ could increase graphitized carbon degree due to the catalytic effect of Co nanoparticles, leading to the improvement of electrical double capacitance by enhanced conductivity [31-33]. The in-situ grown ZIF-67 precursor was agglomerated, yielding the formation of porous carbon foam. We introduced post-electroetching with mixed acid at a high voltage to 
eliminate the embedded metallic Co nanoparticles in carbon foam and oxidize the external walls of carbon foam (see Fig. 1a). The SEM images in Fig. 1b show that triangular-shaped MOF nanowalls with an average thickness of $120 \mathrm{~nm}$ are grown on carbon fibers. The morphology might be analogously associated to the layered crystal structure of zinc as demonstrated by previous studies [19,34,35]. During calcination, three-dimensional graphitic foam-like carbon with plentiful visible macro-pores surrounded by Co nanoparticles (10-30 nm) was formed, demonstrating synchronous decomposition into metallic Co (Fig. 1c1-c2). Fig. 1d1-d2 show SEM image of PCF/CC after electro-etching (EPCF/CC), evidencing smooth surface and abundant open pores on the carbon foam. This feature ensures the availability of active channels for ion storage. It is noteworthy that the average size of macro-pores, serving as ion-buffering reservoirs, was not changed at all. The outermost surface of carbon foam tends to be partly exfoliated from the core, which might contribute to the surface chemical reactivity of carbon foam during the electrochemical process. The porous surface, in combination with the open channels, allows better flexibility to buffer the internal strain and offers accessible inner surface area for the rapid diffusion of electrolyte ions. Apart from high capacitance, the additional overpotential is also crucial for promoting energy density. Taking this into account, electrochemical reduction was conducted using CV cycles. It is important to note that the introduced sodium dopant did not alter the microstructure, as depicted in Fig. S1. EDS elemental mapping images (Fig. 1e) exhibit the uniform incorporation of multi-components $\mathrm{O}$, $\mathrm{N}, \mathrm{S}$, and $\mathrm{Na}$ into the well-developed carbon matrix, which resulted in an excellent synergistic effect to improve the electrochemical performance. Detailed structures of RPCF/CC are revealed by TEM as shown in Fig. 1f, which provides an evidence for a fully open framework with abundant micro-/meso-pores. The typical ring feature from selected-area electron diffraction (SAED) pattern indicates the random arrangement of RPCF. The parallel fringe with spacing is measured as $0.34 \mathrm{~nm}$, consistent with the d-spacing of (002) plane in graphite carbon. As depicted in Fig. 2a, the BET results reveal that the RPCF/CC possesses higher specific surface area and widened pore size when compared with PCF/CC sample, attributing to the exposure of more active sites after removing Co nanoparticles. In addition, the typical type-IV adsorption-desorption isotherm of RPCF/CC based on $\mathrm{N}_{2}$ uptake at a relative pressure of $\mathrm{P} / \mathrm{P}_{0}>0.5$ further verifies the existence of both micro-pores and meso-pores. Hierarchical porous structure not only ensures fast ion diffusion by shortening the diffusion pathways through macro-pores, but also utilizes inner mesoporous as ion-highways for fast ion transmission, and micro-porous textures for charge accommodation [36,37].

The phase purity and crystal structure were examined by XRD. As seen in Fig. $2 \mathrm{~b}$, the main peaks are assignable to graphitic carbon and Co $f c c$ crystal. The sharp peak centered at around $25^{\circ}$ corresponds to typical (002) interlayer peak of carbon foam and carbon cloth substrate, which well-conform to above TEM observation. The peak becomes wider and shift towards smaller angle after electro-etching and reduction, indicating the slightly increase of the defects and inter-lamellar d-spacing in carbon framework [37]. Three well resolved characteristic peaks at $44.3^{\circ}, 51.5^{\circ}$, and $75.9^{\circ}$ belong to the $f c c$ structured metallic Co (JCPDS No. 15-0806). A small amount of Co was oxidized to cobalt monoxide ( $\mathrm{CoO}$ ), evidenced by the presence of small diffraction peak derived from $f c c \mathrm{CoO}$ phase [31]. In case of RPCF/CC, no noticeable signals are observed for $\mathrm{Co}$ and $\mathrm{CoO}$ species, evidencing the fully diminished content of $\mathrm{Co}$ and $\mathrm{CoO}$ residues. Raman spectroscopy was further performed to monitor the defects of the sample (Fig. 2c). The two prominent bands located at $1346 \mathrm{~cm}^{-1}$ and $1594 \mathrm{~cm}^{-1}$ associate to $\mathrm{D}$ band from disordered carbon $\left(\mathrm{A}_{1 \mathrm{~g}}\right.$ mode) and $\mathrm{G}$ band from ordered $\mathrm{sp}^{2}$-hybridized carbons $\left(E_{2 g}\right.$ mode), respectively [38]. In addition, the appearance of weak $2 \mathrm{D}\left(2686 \mathrm{~cm}^{-1}\right)$ and D $+\mathrm{G}\left(2940 \mathrm{~cm}^{-1}\right)$ band indicates an amorphous structure with a highly disordered state in our MOFs-derived PCF/CC and RPCF/CC [39]. Notably, the RPCF/CC with an intensified degree of graphitization and defects can be demonstrated by the rise of $\mathrm{I}_{\mathrm{D}} / \mathrm{I}_{\mathrm{G}}$ value and decay of $I_{2 D} / I_{G}$ value (Fig. $2 d$ ), which is consistent with the XRD results. Such structural distortion introduces multiple defect sites and edges on the surface of carbon foam, resulting in the generation of a larger number of capacitive sites and ultimately improving the device performance.

The X-ray photoelectron spectroscopy (XPS) of RPCF/CC sample presents characteristic signals of $\mathrm{C} 1 \mathrm{~s}, \mathrm{O} 1 \mathrm{~s}, \mathrm{~N} 1 \mathrm{~s}, \mathrm{~S} 2 \mathrm{p}$, and $\mathrm{Na} 1 \mathrm{~s}$

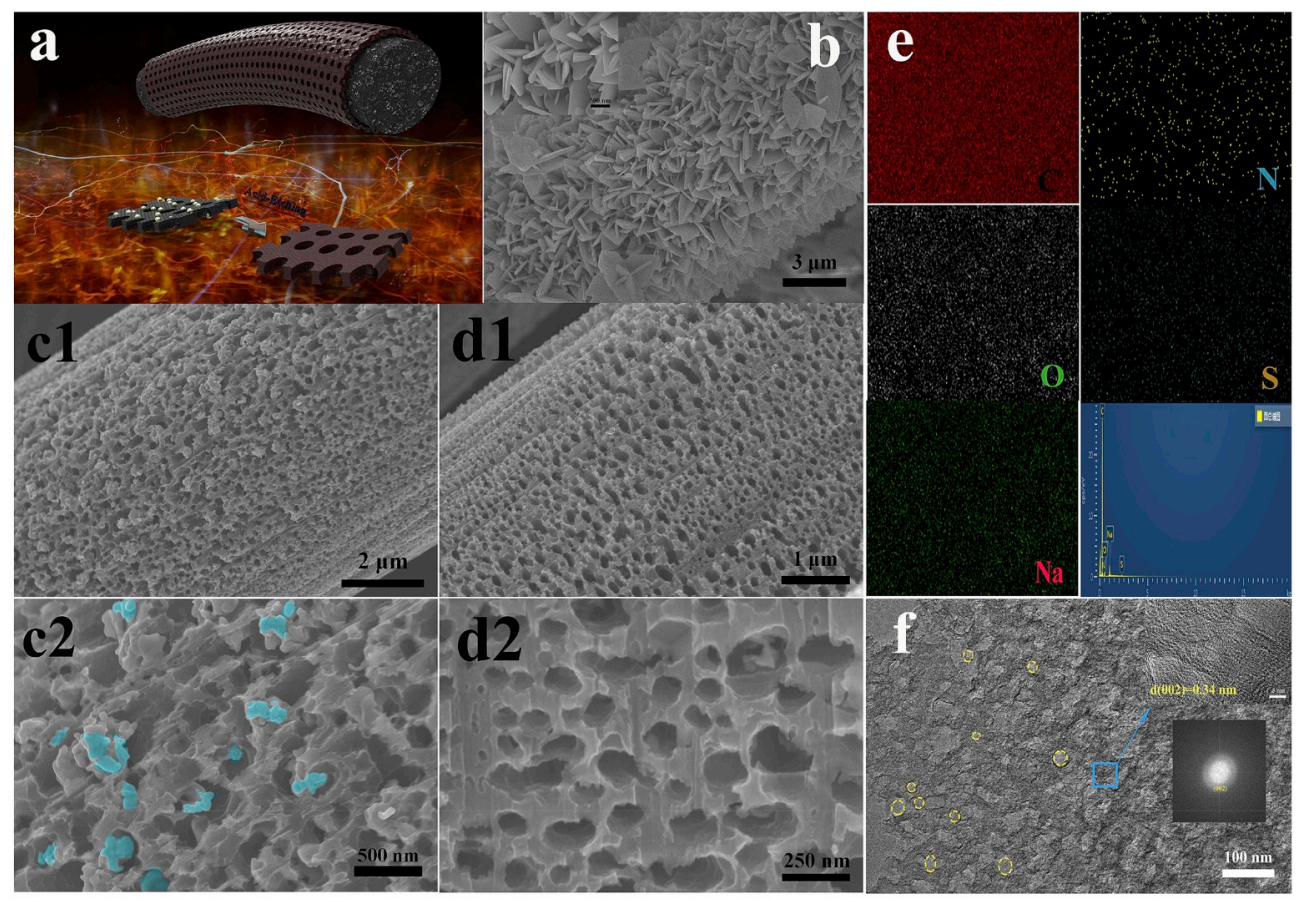

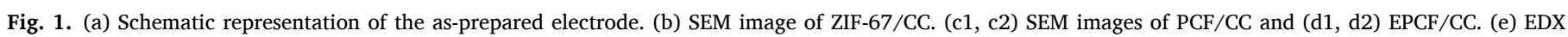

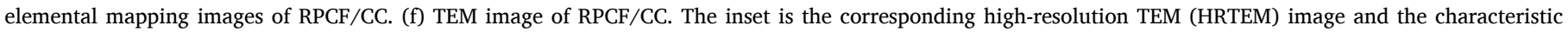
SAED pattern. 

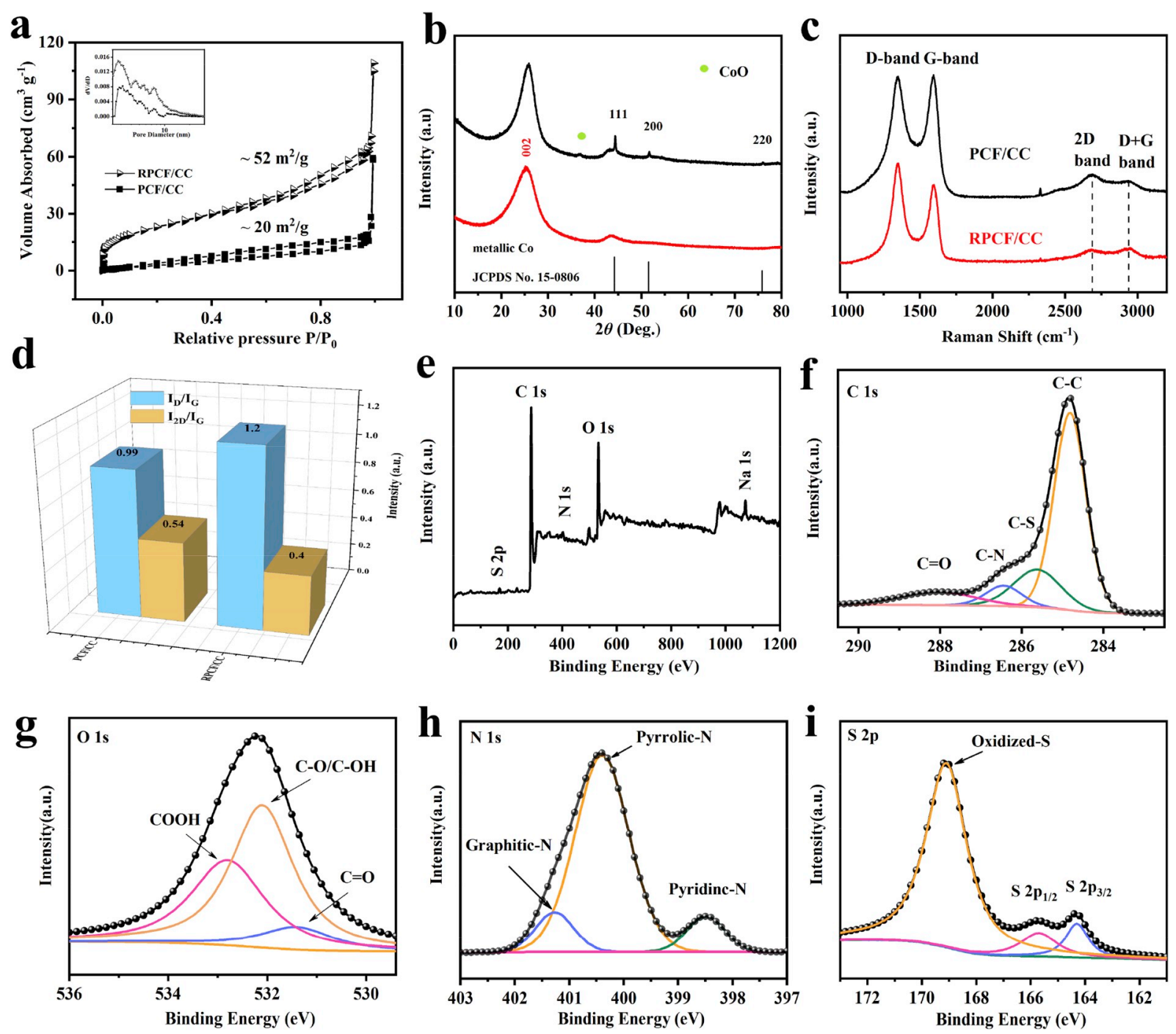

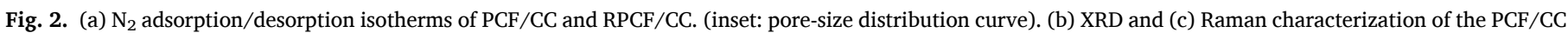

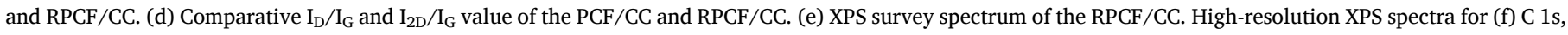
(g) O 1s, (h) N 1s, and (i) S 2p.

(Fig. 2e), in which the contents of $\mathrm{O}, \mathrm{N}$, and $\mathrm{S}$ elements are quantified as 15.4 At \%, 1.23 At \%, and 1.19 At \%, respectively. Through employing Gaussian fitting approach, the C1s spectrum (Fig. 2f) can be deconvoluted into four peaks such that 284.8, 285.6, 286.4, and $288.0 \mathrm{eV}$ are attributed to $\mathrm{C}-\mathrm{C}, \mathrm{C}-\mathrm{S}, \mathrm{C}-\mathrm{N}$, and $\mathrm{C}=\mathrm{O}$ respectively $[40,41]$. The presence of $\mathrm{C}-\mathrm{S}$ and $\mathrm{C}-\mathrm{N}$ further reflects that $\mathrm{N}$ and $\mathrm{S}$ have been successfully doped into carbon framework. The high-resolution O 1s XPS spectrum in Fig. $2 \mathrm{~g}$ shows three peaks with binding energies of 531.4, 531.1, and $532.8 \mathrm{eV}$, indexing to $\mathrm{C}=\mathrm{O}, \mathrm{C}-\mathrm{O} / \mathrm{C}-\mathrm{OH}$, and $\mathrm{COOH}$ groups respectively, which also are believed to offer pseudocapacitance and high hydrophilicity [42]. Two peaks corresponding to pyridinic-N $(398.5 \mathrm{eV})$, pyrrolic-N $(400.4 \mathrm{eV})$ are discovered, accompanied by a graphitic-N $(401.3 \mathrm{eV})$ group (Fig. $2 \mathrm{~h}$ ) and for S dopant, S 2p peak is split into three peaks, showing different types of sulfur species (Fig. 2i) [43]. As reported, pyridinic-N, which replaces carbon atom at the edge of graphite layer, and graphitic-N, which supersedes carbon atom within the graphite layer, indicate that $\mathrm{N}$ atoms are partially integrated into carbon matrix rather than physical combinations, thus this framework is anticipated to efficiently boost electronic conductivity as already been observed elsewhere $[43,44]$. We believe that the electro-etching process possibly induce exfoliation that could be attributed to the strong peak $(169.1 \mathrm{eV})$, reflecting the partially oxidized sulfur species or residual sulfate groups on the surface [45]. Furthermore, the largely expanded integrated area of RPCF/CC in Fig. S2a indicates an increasing content of $\mathrm{Na}$ component and the atomic content of $\mathrm{Na}(1.42 \mathrm{At} \%)$ is in consistency with that calculated from EDS analysis (1.96\%). The maximum areal capacitance of RPCF/CC can be confirmed in Fig. S2b with larger CV enclosed curve area than that $\mathrm{PCF} / \mathrm{CC}$ and pristine CC. For comparison, the LSV curves are provided in Fig. S2c, evidencing that the HER activity of RPCF/CC becomes less pronounced as indicated by a gentle slope at low potential region. Such a phenomenon suggests that adsorption of $\mathrm{H}^{+}$onto the surface of porous carbon foam was deterred by the adsorption of $\mathrm{Na}^{+}$with cycling, which restricts the reduction of water.

To confirm the suitable operating voltage of the as-synthesized RPCF/CC, CV technique was conducted by varying potential windows from -1.1 to $-1.5 \mathrm{~V}$ in $1 \mathrm{M} \mathrm{Na}_{2} \mathrm{SO}_{4}$ electrolyte. Fig. 3a displays an obvious symmetrical rectangular-like shape at the potential window $\geq-1.3 \mathrm{~V}$ vs. SCE, indicating an excellent electrochemical reversibility. Moreover, the ratio of accumulative charge $\left(Q_{c}\right)$ on electrode during charging to the amount of discharge $\left(Q_{d}\right)$ can be used to estimate the voltage stability by introducing $S$-value as: $S=1-Q_{c} / Q_{d}[46]$. When the applied voltage is lower than $-1.3 \mathrm{~V}$, the $\mathrm{S}$-value increases due to a rapid rising of anodic current near potential limit. Thus, an optimum 

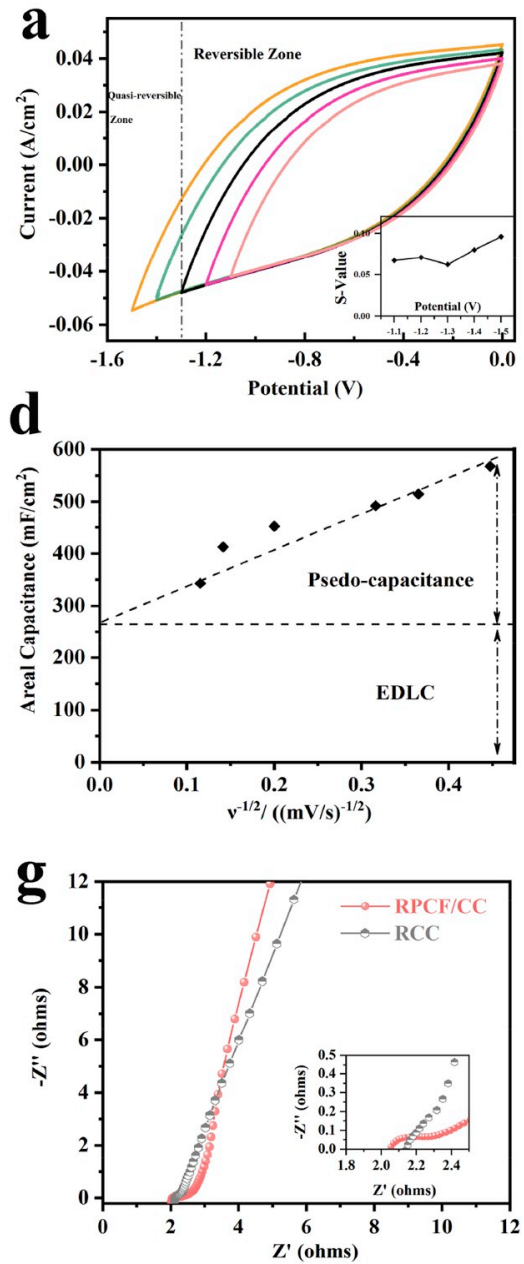

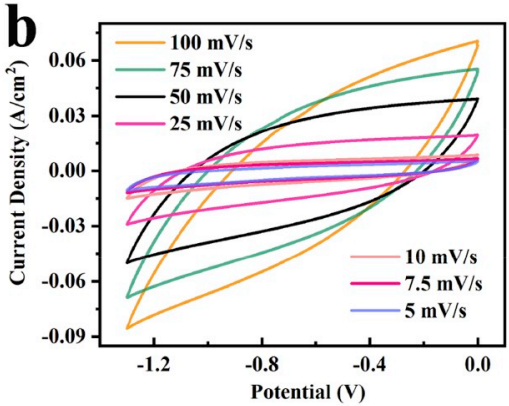

e
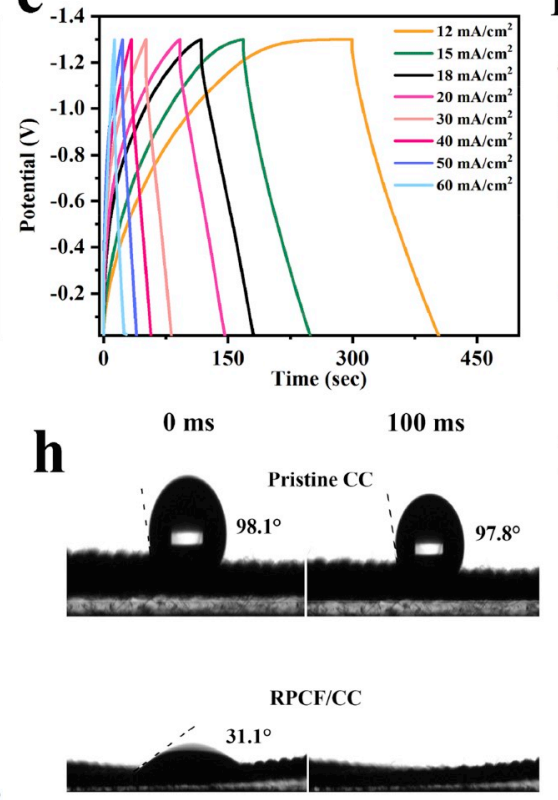

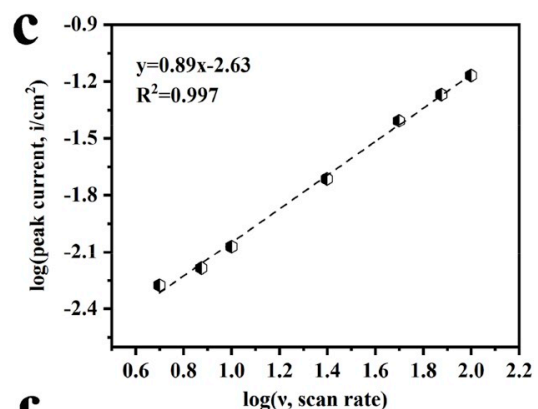

f
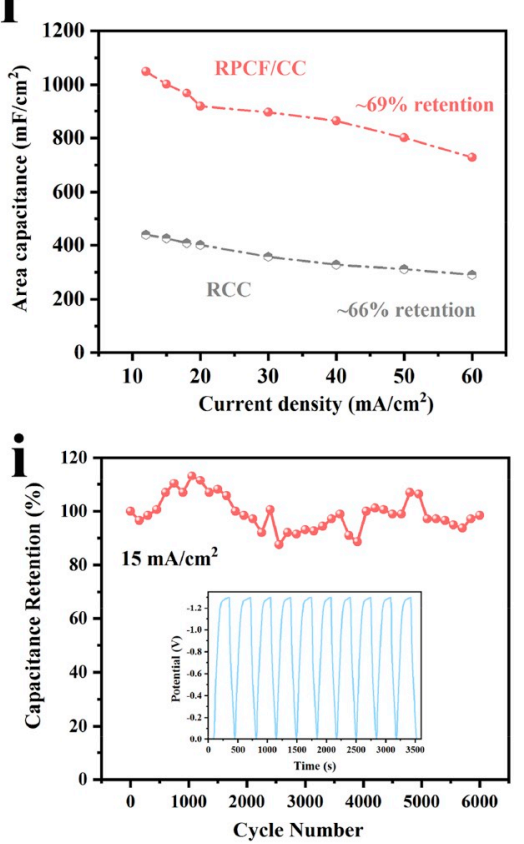

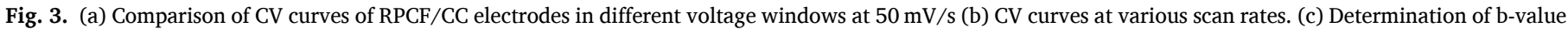

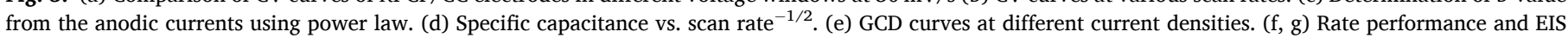

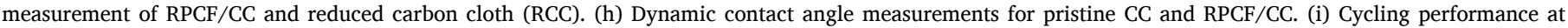
$15 \mathrm{~mA} / \mathrm{cm}^{2}$, the inset shows last $10 \mathrm{GCD}$ curves.

potential window of $-1.3 \mathrm{~V}$ is determined by a minimum S-value of 0.062. In the case of the RPCF/CC, all CV curves exhibit similar loops with almost no distortion at the sweep rates from 5 to $100 \mathrm{mV} / \mathrm{s}$, indicating that a fast electrochemical response and a small equivalent series resistance with rapid charging-discharging features (Fig. 3b). The amount of capacitive contribution was analyzed quantitatively using $\mathrm{CV}$ curves at different scan rates by power-law relationship: $i=a \nu^{b}$ (where a and $b$ are adjustable parameters) [47]. In a defined condition, the exponent will take $\mathrm{a} b$ value between 0.5 (diffusion-controlled reaction) and 1 (surface-controlled reaction). As shown in Fig. 3c, the value of b determined from the slope of $\log (i)-\log (\nu)$ plot is 0.89 , exhibiting a surface-dominated kinetic process $[5,48]$. Pure EDLC can be separated by a linear plot of the area capacitance vs. scan rate $\mathrm{r}^{-1 / 2}$ as shown in Fig. 3d [49,50]. Rate capability of RPCF/CC can be reconfirmed through high EDLC value of $265 \mathrm{mF} / \mathrm{cm}^{2}$, obtained from the Y-intercept of the linear fitted plot. This finding also indicates that surface functional groups deviated from electro-etching can take place in reversible redox reactions to produce extra pseudo-capacitance during the test process, as shown in the following Eqns. (1)-(3) [51].

$-\mathrm{C}-\mathrm{OH} \leftrightarrow-\mathrm{CO}+\mathrm{H}^{+}+\mathrm{e}^{-}$

$-\mathrm{COOH} \leftrightarrow-\mathrm{COO}+\mathrm{H}^{+}+\mathrm{e}^{-}$

$-\mathrm{CO}+\mathrm{e}^{-} \leftrightarrow-\mathrm{C}-\mathrm{O}^{-}$
Due to the relatively low amount of functional groups on the surface of RPCF/CC, it could not present strong redox peaks on CV curves. Furthermore, all GCD curves of RPCF/CC display nearly symmetry with triangular shapes at different current densities (Fig. 3e). The calculated area capacitance of RPCF/CC can reach up to $1049 \mathrm{mF} / \mathrm{cm}^{2}$ at $12 \mathrm{~mA}$ / $\mathrm{cm}^{2}$, exceeding the levels of many similar binder-free electrodes at the same or even smaller current density (Table S1). To illustrate the maximized rate performance, ultrahigh current density of $60 \mathrm{~mA} / \mathrm{cm}^{2}$ is supplied with superb capacitance retention of $69 \%$. For comparison, reduced carbon cloth (RCC) was also prepared by a similar process without loading ZIF-67. As expected, the RPCF/CC shows superior discharge specific capacity and rate performance than RCC (Fig. 3f, S2d), which is due to the good synergistic effect between CC and RPCF with the plentiful pores and surface functional groups [52].

The excellent electrochemical performance of electrode was further validated by interpenetrating the electrical conductivity and ion diffusion. The intercept on real axis and the radius of semicircle reflect the equivalent series resistance $\left(R_{s}\right)$ and electronic charge transfer resistance $\left(\mathrm{R}_{\mathrm{ct}}\right.$ ), respectively (Fig. 3g, S3). RPCF/CC exhibits a smaller diameter of the semicircle, corresponding to a smaller value of $0.296 \Omega$, and a larger slope in low-frequency region, related to the diffusion-limited process, than those of RCC, indicating a better charge transfer capability as well as near-ideal capacitive behavior [53]. Different from pristine CC, which is usually hydrophobic with an almost unchanged contact angle of $\approx 98.1^{\circ}, \mathrm{RPCF} / \mathrm{CC}$ is quite hydrophilic with an initial contact angle of 
$31.1^{\circ}$ and the droplet is completely absorbed within $100 \mathrm{~ms}$ (Fig. 3h). A very good surface wettability also allows enhanced interactions between the electrolyte ions and the exposed surfaces by electro-sorption, which favors effective formation of electric double layers. Remarkable capacitance retention is a crucial parameter for practical application. It is noteworthy that, in $1 \mathrm{M} \mathrm{Na}_{2} \mathrm{SO}_{4}$ electrolyte, the RPCF/CC electrode displays a desirable retention of $98.4 \%$ to the original specific capacitance after 6000 cycles at $15 \mathrm{~mA} / \mathrm{cm}^{2}$ with optimum potential window of $-1.3-0 \mathrm{~V}$ (Fig. 3i). Additionally, the stable GCD curves for the last 10 cycles (inset of Fig. 3i) also confirm the satisfied endurance of RPCF/CC for practical applications.

The superior electrochemical performance of RPCF/CC can be attributed to the following points: (1) After thermal treatment, the proper porosity can be reserved, which not only ensures enough surface area and channels for the transmission of ions and electrons, but also provide abundant contact interfaces between the layers of the electrode and the electrolyte [54]. (2) In situ $\mathrm{N}$ incorporation into endohedral pores during synthesis can induce a partial positive charge on the neighboring carbon atoms providing in-depth penetration of the electrolyte and resulting in enhanced surface utilization [22]. (3) Beside removing the Co nanoparticles, the following acid etching and exfoliation resulted in a hydrophilic high-polarized surface with reversible pseudo-sites, leading to the decreased interfacial charge transfer resistance and producing extra pseudocapacitive contributions. The high-wettability in the as-prepared state increases the migration rate of ions on the surface, which favors the effective formation of electric double layers, and eliminates the routine use of binders for the electrode preparation. A further advantage is that adsorbed $\mathrm{Na}^{+}$ions and reducing oxygen functionalities induced by the electro-reduction procedure can effectively inhibit the HER activity for a broad negative potential window of $-1.3-0 \mathrm{~V}$ [9].

The electrical performance of ASC is usually restricted by the electrode with lower specific capacitance owing to the large changes in specific capacitance values between the cathode and anode [7]. To fabricate high-performance ASC, $\mathrm{H}-\mathrm{MnO}_{2} / \mathrm{CC}$ (Fig. 4a) with mass loading of $\sim 3 \mathrm{mg}$ was synthesized as cathode to match the charge storage capability. Fig. $4 \mathrm{~b}$ shows $\mathrm{RPCF} / \mathrm{CC}$ and $\mathrm{H}-\mathrm{MnO}_{2} / \mathrm{CC}$ electrode in separate working potential region of $-1.3-0 \mathrm{~V}$ and $0-1 \mathrm{~V}$ at a scan rate of $25 \mathrm{mV} / \mathrm{s}$, respectively. According to similar capacitance calculated from the enclosed CV loops, a stable window up to $2.3 \mathrm{~V}$ can be inferred for this obtained ASC. As expected, no steep current was observed in CV curves until the operating voltage is beyond $2.3 \mathrm{~V}$ (Fig. 4c). The close-to-rectangular shape can be well maintained at a high scan rate of $100 \mathrm{mV} / \mathrm{s}$, which identify the good reversibility of $\mathrm{H}-\mathrm{MnO}_{2} / \mathrm{CC} / / \mathrm{RPCF} / \mathrm{CC}$ (Fig. 4d). This behavior is in good agreement with the charging/discharge performance, exhibiting nearly linear variation at various current densities (Fig. S4). Based on the GCD curve, the calculated total area capacitance of the ASC reaches 1106 and $704 \mathrm{mF} / \mathrm{cm}^{2}$ at the current densities of 4 and $40 \mathrm{~mA} / \mathrm{cm}^{2}$, respectively, implying an exceptional rate capability. Together, the achievement of high specific capacitance, outstanding rate capability, and wide voltage window of $2.3 \mathrm{~V}$ pave the way for ASC with high-level energy and power performance. As depicted in Fig. 4f, the ASC can deliver a volumetric energy density of up to $10.07 \mathrm{mWh} / \mathrm{cm}^{3}$ at a volumetric power density of $55.8 \mathrm{~mW} / \mathrm{cm}^{3}$, which outperforms many representative symmetric supercapacitors (SSC) and ASCs operated at various potential window and even comparable to the average value of thin-film lithium battery $\left(0.3-10 \mathrm{mWh} / \mathrm{cm}^{3}\right)$. Furthermore, the specific capacitance of ASC retained $93.4 \%$ of its initial value after 3000 cycles (Fig. S5a), manifesting its high reversibility. As a result of the high voltage available with our capacitor, a single device with small internal resistance provides sufficient potential to light up a red LED (Fig. S5b), indicative of its commercial prospect.

\section{Conclusions}

In summary, we have successfully fabricated RPCF/CC with both high area capacitance and widened voltage window by using electroetching and reduction process, which is a promising anode for asymmetric supercapacitors. The as-prepared carbon foam with hierarchical porous structure and an intensified degree of graphitization delivers ultrahigh area capacitance, high surface wettability, and superb cycling
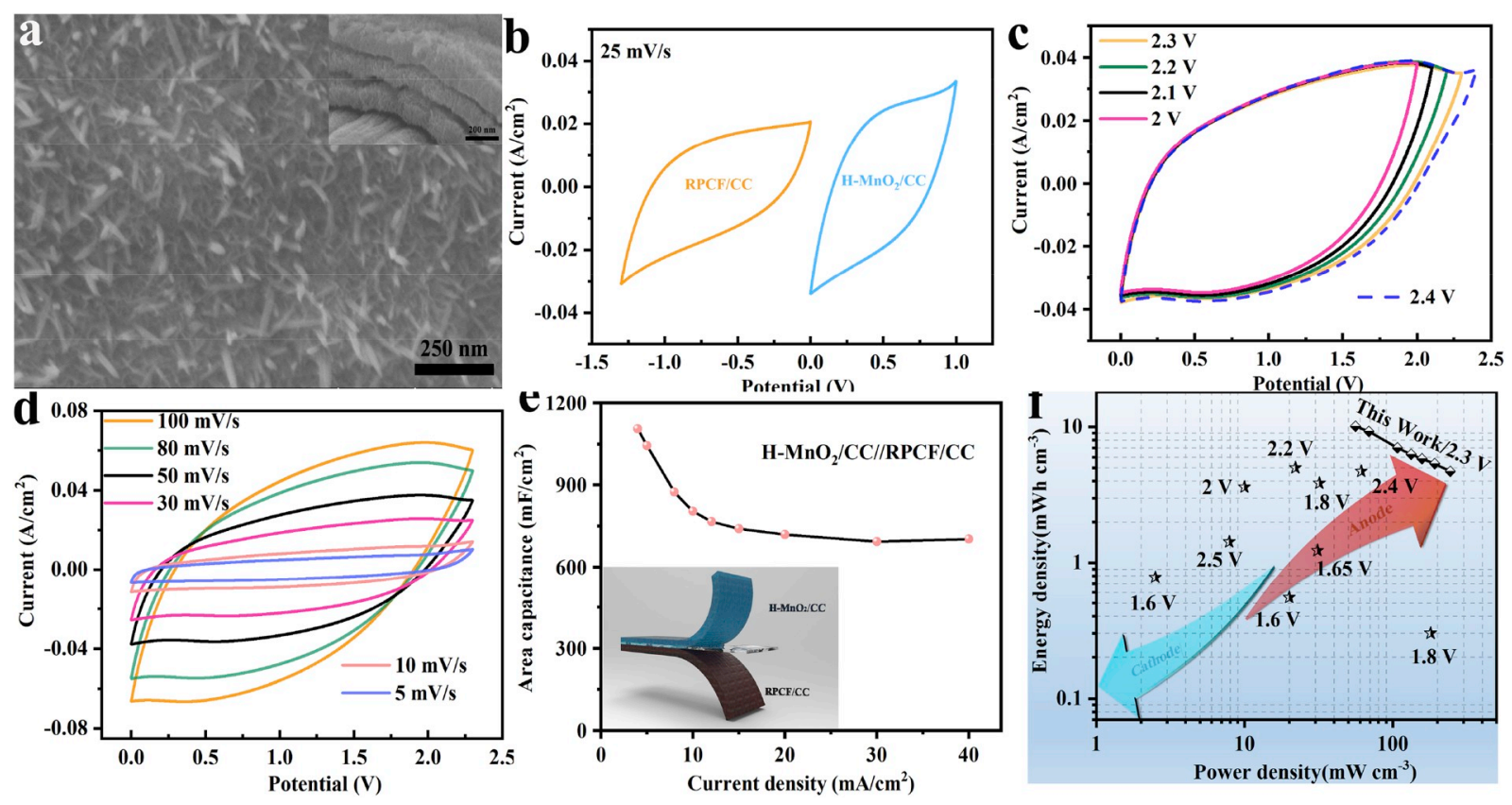

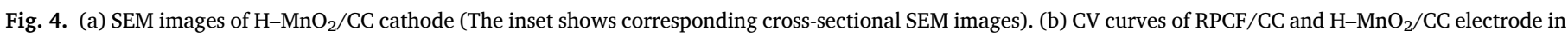

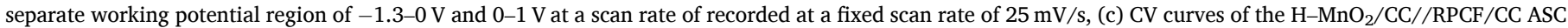

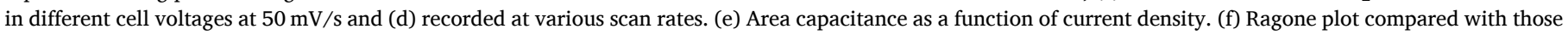

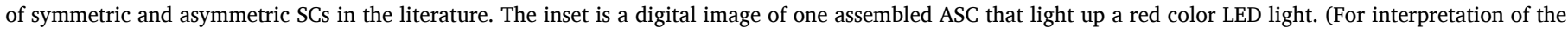
references to color in this figure legend, the reader is referred to the Web version of this article.) 
stability. Furthermore, a high-performance ASC device with maximum operating voltage of $2.3 \mathrm{~V}$ was assembled by matching the anode with $\mathrm{H}-\mathrm{MnO}_{2} / \mathrm{CC}$ cathode, comparable to those devices with in organic electrolytes. The device presents excellent electrochemical performance in terms of energy density (up to $10.07 \mathrm{mWh} / \mathrm{cm}^{3}$ at a volumetric power density of $55.8 \mathrm{~mW} / \mathrm{cm}^{3}$ ). Our strategy, considering overall control, can be further extended to other carbonaceous materials and hence could open up new opportunities in designing high-voltage supercapacitors.

\section{Acknowledgment}

This work was supported by the Fund of State Key Laboratory of Multiphase Complex Systems (No. MPCS-2019-A-03) and Center for Mesoscience, Institute of Process Engineering, Chinese Academy of Sciences (No. COM2016A003).

\section{Appendix A. Supplementary data}

Supplementary data to this article can be found online at https://doi. org/10.1016/j.jpowsour.2019.227066.

\section{References}

[1] B. Yao, J. Zhang, T. Kou, Y. Song, T. Liu, Y. Li, Adv. Sci. 4 (2017) 1700107.

[2] D. Yu, Q. Qian, L. Wei, W. Jiang, K. Goh, J. Wei, J. Zhang, Y. Chen, Chem. Soc. Rev. 44 (2015) 647-662.

[3] N. Choudhary, C. Li, J. Moore, N. Nagaiah, L. Zhai, Y. Jung, J. Thomas, Adv. Mater. 29 (2017).

[4] A. Muzaffar, M.B. Ahamed, K. Deshmukh, J. Thirumalai, Renew. Sustain. Energy Rev. 101 (2019) 123-145.

[5] F. Wang, X. Wu, X. Yuan, Z. Liu, Y. Zhang, L. Fu, Y. Zhu, Q. Zhou, Y. Wu, W. Huang, Chem. Soc. Rev. 46 (2017) 6816-6854.

[6] J. Liu, L. Zhang, H.B. Wu, J. Lin, Z. Shen, X.W.D. Lou, Energy Environ. Sci. 7 (2014) 3709-3719.

[7] R. Sahoo, D.T. Pham, T.H. Lee, T.H.T. Luu, J. Seok, Y.H. Lee, ACS Nano 12 (2018) 8494-8505.

[8] G. Wang, L. Zhang, J. Zhang, Chem. Soc. Rev. 41 (2012) 797-828.

[9] T. Xiong, T.L. Tan, L. Lu, W.S.V. Lee, J. Xue, Adv. Energy Mater. 8 (2018) 1702630.

[10] M. Yu, Y. Lu, H. Zheng, X. Lu, Chem. Eur J. 24 (2018) 3639-3649.

[11] Z. Li, L. Zhang, B. Li, Z. Liu, Z. Liu, H. Wang, Q. Li, Chem. Eng. J. 313 (2017) $1242-1250$.

[12] B. Liu, H. Shioyama, H. Jiang, X. Zhang, Q. Xu, Carbon 48 (2010) 456-463.

[13] Y. Lv, L. Gan, M. Liu, W. Xiong, Z. Xu, D. Zhu, D.S. Wright, J. Power Sources 209 (2012) 152-157.

[14] Z. Wu, L. Li, J.m. Yan, X.b. Zhang, Adv. Sci. 4 (2017) 1600382.

[15] F. Zhang, T. Liu, M. Li, M. Yu, Y. Luo, Y. Tong, Y. Li, Nano Lett. 17 (2017) 3097-3104.

[16] L. Ma, J. Liu, S. Lv, Q. Zhou, X. Shen, S. Mo, H. Tong, J. Mater. Chem. 7 (2019) 7591-7603.

[17] A. Burke, M. Miller, J. Power Sources 196 (2011) 514-522.

[18] M.H. Naveen, K. Shim, M.S.A. Hossain, J.H. Kim, Y.B. Shim, Adv. Energy Mater. 7 (2017) 1602002.

[19] W. Ren, H. Zhang, C. Guan, C. Cheng, Adv. Funct. Mater. 27 (2017) 1702116.
[20] R.R. Salunkhe, Y.V. Kaneti, Y. Yamauchi, ACS Nano 11 (2017) 5293-5308.

[21] Y. Deng, Y. Xie, K. Zou, X. Ji, J. Mater. Chem. 4 (2016) 1144-1173.

[22] D. Mohapatra, G. Dhakal, M.S. Sayed, B. Subramanya, J.-J. Shim, S. Parida, ACS Appl. Mater. Interfaces 11 (2019) 8040-8050.

[23] D. Hulicova-Jurcakova, A.M. Puziy, O.I. Poddubnaya, F. Suárez-García, J. M. Tascón, G.Q. Lu, J. Am. Chem. Soc. 131 (2009) 5026-5027.

[24] Y. He, Y. Zhang, X. Li, Z. Lv, X. Wang, Z. Liu, X. Huang, Electrochim. Acta 282 (2018) 618-625.

[25] C. Shu, Y. Lin, D. Su, J. Mater. Chem. 4 (2016) 2128-2136.

[26] Z. Li, Z. Xu, X. Tan, H. Wang, C.M.B. Holt, T. Stephenson, B.C. Olsen, D. Mitlin, Energy Environ. Sci. 6 (2013) 871-878.

[27] L. Yao, Q. Wu, P. Zhang, J. Zhang, D. Wang, Y. Li, X. Ren, H. Mi, L. Deng, Z. Zheng, Adv. Mater. 30 (2018) 1706054

[28] T.Y. Ma, J. Ran, S. Dai, M. Jaroniec, S.Z. Qiao, Angew. Chem. Int. Ed. 54 (2015) 4646-4650.

[29] X. Lu, M. Yu, G. Wang, Y. Tong, Y. Li, Energy Environ. Sci. 7 (2014) 2160-2181.

[30] J. Zhang, J. Sun, T. Ahmed Shifa, D. Wang, X. Wu, Y. Cui, Chem. Eng. J. 372 (2019) 1047-1055.

[31] N.L. Torad, M. Hu, S. Ishihara, H. Sukegawa, A.A. Belik, M. Imura, K. Ariga, Y. Sakka, Y. Yamauchi, Small 10 (2014) 2096-2107.

[32] Y. Lü, Y. Wang, H. Li, Y. Lin, Z. Jiang, Z. Xie, Q. Kuang, L. Zheng, ACS Appl. Mater. Interfaces 7 (2015) 13604-13611.

[33] M.L. Yue, C.Y. Yu, H.H. Duan, B.L. Yang, X.X. Meng, Z.X. Li, Chem. Eur J. 24 (2018) 16160-16169.

[34] G. Fang, J. Zhou, C. Liang, A. Pan, C. Zhang, Y. Tang, X. Tan, J. Liu, S. Liang, Nano Energy 26 (2016) 57-65.

[35] R. Chen, J. Yao, Q. Gu, S. Smeets, C. Baerlocher, H. Gu, D. Zhu, W. Morris, O. M. Yaghi, H. Wang, Chem. Commun. 49 (2013) 9500-9502.

[36] S. Dutta, A. Bhaumik, K.C.-W. Wu, Energy Environ. Sci. 7 (2014) 3574-3592.

[37] R. Shi, C. Han, H. Li, L. Xu, T. Zhang, J. Li, Z. Lin, C.-P. Wong, F. Kang, B. Li, J. Mater. Chem. 6 (2018) 17057-17066.

[38] C. Ma, W. Zhang, Y.-S. He, Q. Gong, H. Che, Z.-F. Ma, Nanoscale 8 (2016) 4121-4126.

[39] Z. Chen, W. Ren, L. Gao, B. Liu, S. Pei, H.-M. Cheng, Nat. Mater. 10 (2011) 424.

[40] S. Zhou, Q.-X. Zhou, H. Su, Y. Wang, Z. Dong, X. Dai, X. Zhang, J. Colloid Interface Sci. 533 (2019) 311-318.

[41] Z.-J. Fan, W. Kai, J. Yan, T. Wei, L.-J. Zhi, J. Feng, Y.-m. Ren, L.-P. Song, F. Wei, ACS Nano 5 (2010) 191-198.

[42] C. Tang, Y. Liu, D. Yang, M. Yang, H. Li, Carbon 122 (2017) 538-546.

[43] J. Zhu, W. Li, S. Li, J. Zhang, H. Zhou, C. Zhang, J. Zhang, S. Mu, Small 14 (2018) 1800563.

[44] W. Gao, X. Feng, T. Zhang, H. Huang, J. Li, W. Song, ACS Appl. Mater. Interfaces 6 (2014) 19109-19117.

[45] A.Z. Yazdi, E.P. Roberts, U. Sundararaj, Carbon 100 (2016) 99-108.

[46] P. Iamprasertkun, C. Tanggarnjanavalukul, A. Krittayavathananon, J. Khuntilo, N. Chanlek, P. Kidkhunthod, M. Sawangphruk, Electrochim. Acta 249 (2017) 26-32.

[47] H. Lindström, S. Södergren, A. Solbrand, H. Rensmo, J. Hjelm, A. Hagfeldt, S. E. Lindquist, J. Phys. Chem. B 101 (1997) 7710-7716.

[48] Q. Xue, H. Gan, Y. Huang, M. Zhu, Z. Pei, H. Li, S. Deng, F. Liu, C. Zhi, Adv. Energy Mater. 8 (2018) 1703117.

[49] Z.-H. Huang, Y. Song, X.-X. Liu, Chem. Eng. J. 358 (2019) 1529-1538.

[50] A. Singh, A. Chandra, Sci. Rep. 5 (2015) 15551.

[51] F. Wang, S. Xiao, Y. Hou, C. Hu, L. Liu, Y. Wu, RSC Adv. 3 (2013) 13059-13084.

[52] Q. Meng, K. Cai, Y. Chen, L. Chen, Nano Energy 36 (2017) 268-285.

[53] F. Lai, J. Feng, R. Yan, G.C. Wang, M. Antonietti, M. Oschatz, Adv. Funct. Mater. 28 (2018) 1801298.

[54] H. Sun, Y. Lian, C. Yang, L. Xiong, P. Qi, Q. Mu, X. Zhao, J. Guo, Z. Deng, Y. Peng, Energy Environ. Sci. 11 (2018) 2363-2371. 